\title{
Metode Simple Additive Weighting (SAW) Dalam Pemilihan Sim Card Provider
}

\author{
Andy Widya Putera ${ }^{1,{ }^{*}}$, Anna Mukhayaroh ${ }^{1}$, Samudi ${ }^{1}$ \\ * Korespondensi: e-mail: andywidya60@gmail.com
}

Program Studi Sistem Informasi; Sekolah Tinggi Manajemen Informatika dan Komputer Nusa Mandiri; Jl. Jatiwaringin Raya No. 2 Kelurahan Cipinang Melayu, Kecamatan Makasar, Jakarta Timur, telp. (021) 8005722; e-mail: andywidya@gmail.com, anna.auh@nusamandiri.ac.id, samudi.smx@nusamandiri.ac.id

Submitted: $\mathbf{7}$ Oktober 2020

Revised: $\mathbf{2 8}$ Oktober $\mathbf{2 0 2 0}$

Accepted: 11 November 2020

Published: 30 November 2020

\section{Abstract}

With the development of technology at this time Sim Card Provider is needed to support community activities. In Indonesia alone many Sim Card Provider many services and also ease of accessing the internet, sonsumers are required to see which Sim Card Provider suits their needs. To overcome the problem of selecting the Sim Card Provider, a Decision Support System will be made using the Simple Additive Weighting (SAW) method using data taken from questionnaires distributed to Sim Card Provider users, which is expected to help in the selection of the appropriate Sim Card Provider with Consumer needs. The author uses six criteria, namely Signal, Price, Internet Package, Internet Connection, Phone Bonus, SMS Bonus. By using five alternatives namely Simpati, XL, Indosat, Smartfren, Three (3). The final result of this study indicated that alternative 5 or Three (3) has the biggest result of 3,245 and alternative 3 namely Indosat has the lowest result among the alternatives which is 2,625.

Keywords: Criteria, Sim Card Provider, Simple Additive Weighting

\section{Abstrak}

Dengan berkembangnya teknologi pada saatini Sim Card Provider sangat dibutuhkan untuk menunjang aktivitas masyarakat. Di Indonesia sendiri banyak Sim Card Provider banyak menyediakan layanan dan juga kemudahan dalam mengakses internet, konsumen dituntut untuk melihat manakah Sim Card Provider yang sesuai dengan kebutuhan. Untuk mengatasi masalah pemilihan Sim Card Provider tersebut maka akan dibuat Sistem Pendukung Keputusan dengan menggunakan Metode Simple Additive Weighting (SAW) dengan menggunakan data yang diambil dari kuesioner yang dibagikan kepada para pengguna Sim Card Provider, yang diharapkan dapat membantu dalam pemilihan Sim Card Provider yang sesuai dengan kebutuhan Konsumen. Penulis menggunakan enam kriteria yaitu Sinyal, Harga, Paket Internet, Koneksi Internet, Bonus Telpon, Bonus Sms. Dengan menggunakan lima alternatif yaitu Simpati, XL, Indosat, Smartfren, Three (3). Hasil akhir dari penelitian ini menunjukan bahwa alternatif 5 atau Three (3) memiliki hasil terbesar yaitu 3,245 dan alternatif 3 yaitu Indosat memiliki hasil terendah diantara alternatif yang ada yaitu 2,625

Kata kunci: Kriteria, Sim Card Provider, Simple Additive Weighting 


\section{Pendahuluan}

Dengan berkembangnya teknologi pada saat ini Sim Card Provider sangat dibutuhkan untuk menunjang aktivitas masyarakat, Sim Card Provider merupakan kartu yang kita gunakan untuk berlangganan pada satu operator seluler. Di Indonesia sendiri banyak Sim Card Provider yang menyediakan layanan dan juga kemudahan dalam mengakses internet dengan berbagai macam kriteria yang ditawarkan masing-masing operator, konsumen dituntut untuk melihat manakah Sim Card Provider yang sesuai dengan kebutuhan.

Untuk mengatasi masalah pemilihan Sim Card Provider tersebut maka akan dibuat Sistem Pendukung Keputusan dengan menggunakan Metode Simple Additive Weighting (SAW), Metode ini dipilih karena mampu menyeleksi alternatif terbaik yang diharapkan dapat membatu dalam pemilihan Sim Card Provider yang sesuai dengan kebutuhan Konsumen.

Sistem pendukung keputusan merupakan proses dari pengambilan keputusan yang harus dibantu oleh komputer untuk pengambilan keputusan dengan menggunakan beberapa data dan model tertentu untuk menyelesaikan suatu masalah yang tidak terstruktur (Prasetio et al., 2020).

Merek adalah nama, istilah, tanda, lambang, atau kombinasinya, yang diartikan untuk mengidentifikasikan barang atau jasa dari salah satu penjual atau kelompok penjual yang membedakan mereka dari para pesaings (Nainggolan, 2018).

Sistem pendukung keputusan dengan menggunakan metode Simple Additive Weighting juga dapat digunakan dalam proses pemilihan laptop, hal ini dilakukan karena banyaknya merk dan tipe laptop yang dijual di pasaran dengan berbagai jenis spesifikasi dan variasi harga dapat membingungkan konsumen dalam memilih laptop yang sesuai dengan kebutuhannya. Hasil dari penelitian tersebut diperoleh hasil jenis laptop Lenovo IP 310-14IKB memiliki nilai tertinggi sebesar 16,2 (Khasanah, 2019).

Oleh karenanya dalam penelitian ini mencoba untuk menerapkan metode Simple Additive Weighting sebagai salah satu metode pendukung keputusan yang digunakan dalam menentukan jenis provider yang tepat bagi konsumen.

\section{Metode Penelitian}

Metode penelitian pada dasarnya adalah cara ilmiah untuk mendapatkan data dengan tujuan dan kegunaan tertentu. Berdasarkan hal tersebut terdapat empat kata kunci yang sangat perlu diperhatikan yaitu cara ilmiah, data, kegunaan dan tujuan (Sugiyono, 2017).

Dengan mengidentifikasi masalah tersebut maka dalam penelitian ini, penulis melakukan tahapan untuk menggapai tujuan dalam penelitian dengan menggunakan metode Simple Additive Weighting (SAW) adapun tahapan - tahapan penelitian yang penulis lakukan : 


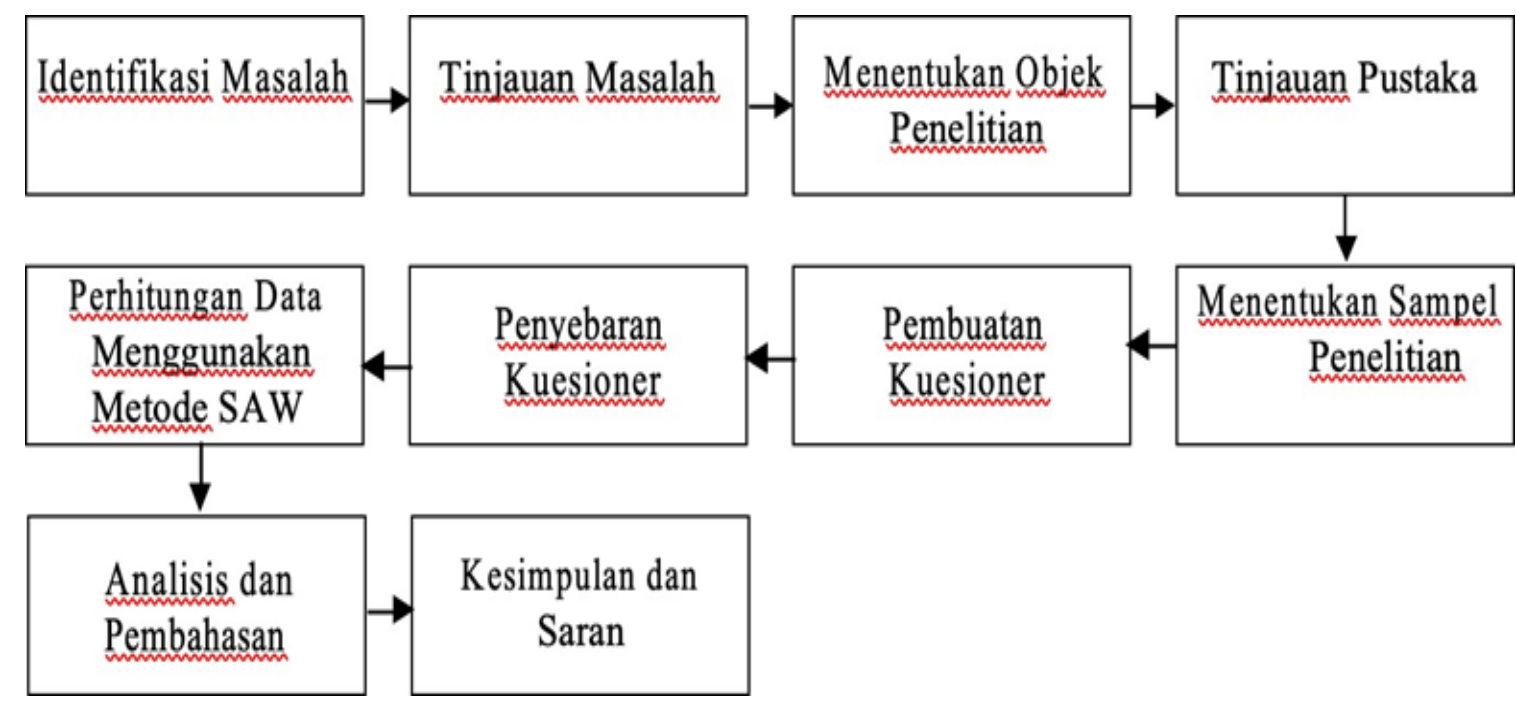

Sumber: Hasil Penelitian (2020)

Gambar 1. Diagram Alur Penelitian

Sistem adalah sebuah kumpulan dari beberapa objek atau unsur yang saling melengkapi dan berhubungan satu sama lain serta berinteraksi untuk mencapai satu tujuan tertentu (Karim \& Purba, 2018). Sistem informasi menurut Jogiyanto dalam (Trianovie, 2018) Sistem adalah suatu jaringan dari prosedur - prosedur yang saling berhubungan satu sama lain dan berkumpul bersama - sama atau untuk menyelesaikan suatu tujuan tertentu.

Sistem pendukung keputusan yaitu sebuah proses pengambilan keputusan yang dibantu oleh komputer untuk pengambil keputusan dengan menggunakan beberapa data dan model tertentu untuk menyelesaikan beberapa masalah yang tidak terstruktur menjadi lebih terstruktur (Prasetio et al., 2020)

Menjelaskan kronologis penelitian, termasuk desain penelitian, prosedur penelitian (dalam bentuk algoritma, Pseudocode atau lainnya), bagaimana untuk menguji dan akuisisi data. Deskripsi dari program penelitian harus didukung referensi, sehingga penjelasan tersebut dapat diterima secara ilmiah. (Herlawati et al., 2018)

Menurut Fishburn dalam. Metode Simple Additive Weighting (SAW) merupakan model penyelesaian masalah yang sering dikenal dengan istilah metode penjumlahan dengan bobot. Konsep dasar dari metode SAW adalah mencari penjumlahan terbobot dari rating kinerja pada setiap alternatif dan semua atribut yang ada. Metode SAW membutuhkan proses normalisasi matriks keputusan $(x)$ ke suatu skala yang dapat di bandingkan dengan semua rating alternatif (Informasi \& Data, 2019). Simple Additive Weighting merupakan suatu metode dalam pengambilan keputusan dimana menjumlahkan bobot maksimum (benefits) dan bobot minimum (cost) sesuai kriteria yang telah ditetapkan sesuai hasil dari kuesioner yang responden isi (Rizan et al., 2019). 
Sim Card merupakan chip yang berbentuk seperti kartu yang diletakkan di dalam handphone. Sim Card ini sering disebut RUIM (Removable User Identity Module). Dengan kartu kecil ini, semua informasi dari operator bisa di simpan di sim card. Anda dapat dengan mudah memindahkan nomor seluler ke ponsel yang berbeda merk (Supardi, 2013).

\section{Hasil dan Pembahasan}

Untuk mencapai tujuan dalam penelitian ini, peneliti menggunakan metode analisis kuantitatif. Analisis kuantitatif dalam penelitian ini membandingkan kriteria dan alternatif yang bisa menghasilkan sebuah keputusan yaitu pemilihan SimCard Provider dengan menggunakan metode Simple Additive Weighting (SAW).

Dalam penelitian ini penulis menyebarkan 50 kuisioner dimana kuesioner ini diisi oleh para pengguna Simcard Provider. Kuisioner yang disebarkan kepada pengguna berjumlah 50 , setiap responden mengisi satu kuisioner yang telah di berikan oleh penulis.

Tabel 1. Profil Responden

\begin{tabular}{|c|c|c|c|}
\hline No. & Klasifikasi Responden & Jumlah & Total \\
\hline \multicolumn{4}{|c|}{ 1. Jenis Kelamin : } \\
\hline & Laki-laki & 29 & 50 \\
\hline & Perempuan & 21 & \\
\hline \multirow{6}{*}{2.} & Usia : & & \\
\hline & $14-20$ & 14 & \\
\hline & $21-30$ & 17 & \\
\hline & $31-40$ & 12 & 50 \\
\hline & $41-50$ & 3 & \\
\hline & $51-60$ & 4 & \\
\hline
\end{tabular}

Berikut ini merupakan kriteria yang dibutuhkan untuk pengambilan keputusan, berdasarkan persyaratan penentuan pemilihan SimCard Provider secara umum, adapun beberapa krieria yang telah ditentukan yaitu Sinyal (C1), Harga (C2), Paket Internet (C3), Koneksi Internet (C4), Bonus Telpon (C5) dan Bonus Sms (C6).

Tabel 2. Ketentuan Kriteria

\begin{tabular}{ll}
\hline Kode & Kriteria \\
\hline C1 & Sinyal \\
\hline C2 & Harga \\
\hline C3 & Paket Internet \\
\hline C4 & Koneksi Internet \\
\hline C5 & Bonus Telpon \\
\hline C6 & Bonus Sms
\end{tabular}

Sumber : Hasil Penelitian (2020) 
Dari kriteria maka dibuat suatu tingkat kepentingan kriteria berdasarkan nilai bobot yang telah ditentukan kedalam bilangan yang digambarkan dalam gambar berikut.

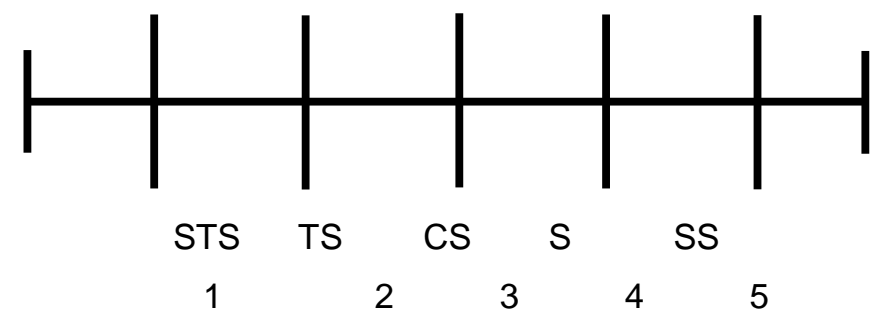

Sumber: Hasil Penelitian (2020)

Gambar 1. Grafik Nilai Bobot

Keterangan :

(STS) Sangat Tidak Setuju $=1$

(TS) Tidak Setuju $\quad=2$

(CS) Cukup Setuju = 3

(S) Setuju $\quad=4$

(SS) Sangat Setuju $\quad=5$

Berdasarkan kriteria diatas maka selanjutnya pemberi keputusan memberikan nilai bobot $\mathrm{W}$ untuk setiap kriteria sebagai berikut :

Tabel 3. Ketentuan Nilai Bobot

\begin{tabular}{lll}
\hline Kriteria & Range (\%) & Bobot \\
\hline C1 & 15 & 0,15 \\
\hline C2 & 25 & 0,25 \\
\hline C3 & 15 & 0,15 \\
\hline C4 & 15 & 0,15 \\
\hline C5 & 15 & 0,15 \\
\hline C6 & 15 & 0,15
\end{tabular}

Sumber : Hasil Pengolahan Data (2020)

Berdasarkan ketentuan kriteria dan nilai bobot pada setiap kriteria yang telah ditentukan, selanjutnya penjabaran bobot dari setiap kriteria yang telah dikonversikan dengan bilangan. Berikut adalah penjabaran yang telah dikonversikan kedalam bilangan seperti tabel 4 .

Tabel 4. Rating Kecocokan

\begin{tabular}{cc}
\hline Parameter & Nilai Bobot \\
\hline $0-8$ & 1 \\
\hline $9-17$ & 2 \\
\hline $18-25$ & 3 \\
\hline $26-33$ & 4 \\
\hline $34-41$ & 5
\end{tabular}

Sumber : Hasil Pengolahan Data (2020) 
Berdasarkan rating kecocokan diatas maka dapat dibuat perhitungan manual berdasarkan hasil perhitungan dari kuesioner.

Tabel 5. Data Hasil Kuesioner Pemilihan SimCard Provider Pada Simpati

\begin{tabular}{cccccc}
\hline & \multicolumn{5}{c}{ Simpati / Alternatif 1 } \\
\cline { 2 - 6 } Sub Kriteria & STS & TS & CS & S & SS \\
& $(1)$ & $(2)$ & $(3)$ & $(4)$ & $(5)$ \\
\hline Sinyal & 0 & 3 & 16 & 20 & 11 \\
\hline Harga & 5 & 9 & 16 & 14 & 6 \\
\hline Paket Internet & 0 & 3 & 24 & 16 & 7 \\
\hline Koneksi Internet & 0 & 2 & 17 & 21 & 10 \\
\hline Bonus Telpon & 1 & 14 & 27 & 8 & 0 \\
\hline Bonus Sms & 1 & 13 & 31 & 5 & 0
\end{tabular}

Sumber : Hasil Pengolahan Data (2020)

Berdasarkan data hasil kuesioner diatas maka dapat dibentuk matriks keputusan (X) yang telah dikonversikan kedalam bilangan sebagai berikut :

Tabel 6. Perantingan Kecocokan Alternatif Simpati

\begin{tabular}{lccccc}
\hline \multirow{2}{*}{ Sub Kriteria } & \multicolumn{7}{c}{ Simpati / Alternatif 1 } \\
\cline { 2 - 6 } & STS & TS & CS & S & SS \\
& $(1)$ & $(2)$ & $(3)$ & $(4)$ & $(5)$ \\
\hline Sinyal & 1 & 1 & 2 & 3 & 2 \\
\hline Harga & 1 & 2 & 2 & 2 & 1 \\
\hline Paket Internet & 1 & 1 & 3 & 2 & 1 \\
\hline Koneksi Internet & 1 & 1 & 2 & 3 & 2 \\
\hline Bonus Telpon & 1 & 2 & 4 & 1 & 1 \\
\hline Bonus Sms & 1 & 2 & 4 & 1
\end{tabular}

Sumber : Hasil Pengolahan Data (2020)

Berdasarkan table perantingan kecocokan alternative diatas maka pembuat keputusan dapat membuat matriks keputusan $(X)$ sebagai berikut :

$$
\left.x=\mid \begin{array}{llllll}
1 & 1 & 1 & 1 & 1 & 1 \\
1 & 2 & 1 & 1 & 2 & 2 \\
2 & 2 & 3 & 2 & 4 & 4 \\
3 & 2 & 2 & 3 & 1 & 1 \\
2 & 1 & 1 & 2 & 1 & 1
\end{array}\right]
$$

Setelah membuat matriks keputusan $(X)$ pemberi keputusan melakukan penggolongan kriteria berdasarkan keuntungan (Benefit) dan biaya (Cost) sebagai berikut :

Tabel 7. Penggolongan Kriteria 


\begin{tabular}{lll}
\hline Kriteria & $\begin{array}{l}\text { Keuntungan } \\
\text { (Benefit) }\end{array}$ & $\begin{array}{l}\text { Biaya } \\
\text { (Cost) }\end{array}$ \\
\hline Sinyal & $\sqrt{ }$ & $\sqrt{ }$ \\
\hline Harga & & \\
\hline Paket Internet & $\sqrt{ }$ & \\
\hline Koneksi Internet & $\sqrt{ }$ \\
\hline Bonus Telpon & $\sqrt{ }$ & \\
\hline Bonus Sms & $\sqrt{ }$ &
\end{tabular}

Sumber : Hasil Pengolahan Data (2020)

Pertama melakukan normalisasi matriks $X$ untuk menghitung nilai masing - masing kriteria sebagai berikut :

a. Untuk kriteria sinyal termasuk kedalam atribut keuntungan (Benefit)

Jadi :

$$
\begin{aligned}
& \mathrm{R}_{11}=\frac{1}{\max \{1 ; 1 ; 2 ; 3 ; 2\}}+{ }_{3}^{1}=0,3 \\
& \mathrm{R}_{21}=\frac{1}{\max \{1 ; 1 ; 2 ; 3 ; 2\}}+{ }_{3}^{1}=0,3 \\
& \mathrm{R}_{31}={ }_{\max \{1 ; 1 ; 2 ; 3 ; 2\}}^{2}+{ }^{2}=0,6 \\
& \mathrm{R}_{41}=\frac{3}{\max \{1 ; 1 ; 2 ; 3 ; 2\}}+{ }^{3}=1 \\
& \mathrm{R}_{51}=\max \{1 ; 1 ; 2 ; 3 ; 2\} \\
& { }^{2}{ }^{2}=0,6
\end{aligned}
$$

b. Untuk kriteria harga termasuk kedalam atribut biaya (Cost)

Jadi :

$$
\begin{aligned}
& \mathrm{R}_{12}=\frac{\min \{1 ; 2 ; 2 ; 2 ; 1\}}{1}+{ }_{1}^{1}=1 \\
& \mathrm{R}_{22}=\frac{\min \{1 ; 2 ; 2 ; 2 ; 1\}}{2}+{ }_{2}^{1}=0,5 \\
& \mathrm{R}_{32}=\frac{\min \{1 ; 2 ; 2 ; 2 ; 1\}}{2}+\frac{1}{2}=0,5 \\
& \mathrm{R}_{42}=\frac{\min \{1 ; 2 ; 2 ; 2 ; 1\}}{2}+\frac{1}{2}=0,5 \\
& \mathrm{R}_{52}=\frac{\min \{1 ; 2 ; 2 ; 2 ; 1\}}{1}+{ }_{1}^{1}=1
\end{aligned}
$$

c. Untuk kriteria paket internet termasuk kedalam atribut keuntungan (Benefit) 


$$
\mathrm{R}_{53}=\frac{1}{\max \{1 ; 1 ; 3 ; 2 ; 1\}}+\frac{1}{3}=0,3
$$

d. Untuk kriteria koneksi internet termasuk kedalam atribut keuntungan (Benefit)

Jadi :

$$
\begin{aligned}
& \mathrm{R}_{14}=\frac{1}{\max \{1 ; 1 ; 2 ; 3 ; 2\}}+\frac{1}{3}=0,3 \\
& \mathrm{R}_{24}=\frac{1}{\max \{1 ; 1 ; 2 ; 3 ; 2\}}+\frac{1}{3}=0,3 \\
& \mathrm{R}_{34}=\frac{2}{\max \{1 ; 1 ; 2 ; 3 ; 2\}}+\frac{2}{3}=0,6 \\
& \mathrm{R}_{44}=\frac{3}{\max \{1 ; 1 ; 2 ; 3 ; 2\}}+\frac{3}{3}=1 \\
& \mathrm{R}_{54}=\frac{2}{\max \{1 ; 1 ; 2 ; 3 ; 2\}}+\frac{2}{3}=0,6
\end{aligned}
$$

e. Untuk kriteria bonus telpon termasuk kedalam atribut keuntungan (Benefit)

Jadi :

$$
\begin{aligned}
& \mathrm{R}_{15}=\frac{1}{\max \{1 ; 2 ; 4 ; 1 ; 1\}}+\frac{1}{4}=0,25 \\
& \mathrm{R}_{25}=\frac{2}{\max \{1 ; 2 ; 4 ; 1 ; 1\}}+\frac{2}{4}=0,5 \\
& \mathrm{R}_{35}=\frac{4}{\max \{1 ; 2 ; 4 ; 1 ; 1\}}+\frac{4}{4}=1 \\
& \mathrm{R}_{45}=\frac{1}{\max \{1 ; 2 ; 4 ; 1 ; 1\}}+\frac{1}{4}=0,25 \\
& \mathrm{R}_{55}=\frac{1}{\max \{1 ; 2 ; 4 ; 1 ; 1\}}+\frac{1}{4}=0,25
\end{aligned}
$$

f. Untuk kriteria bonus sms termasuk kedalam atribut keuntungan (Benefit) 
Jadi :

$$
\begin{aligned}
& \mathrm{R}_{16}=\frac{1}{\max \{1 ; 2 ; 4 ; 1 ; 1\}}+{ }^{1}=0,25 \\
& \mathrm{R}_{26}=\frac{2}{\max \{1 ; 2 ; 4 ; 1 ; 1\}}+{ }^{2}=0,5 \\
& \mathrm{R}_{36}=\frac{4}{\max \{1 ; 2 ; 4 ; 1 ; 1\}}+{ }^{4}=1 \\
& \mathrm{R}_{46}=\frac{1}{\max \{1 ; 2 ; 4 ; 1 ; 1\}}+{ }^{1}=0,25 \\
& \mathrm{R}_{56}=\frac{1}{\max \{1 ; 2 ; 4 ; 1 ; 1\}}+{ }^{1}=0,25
\end{aligned}
$$

Kemudian dari hasil normalisasi diatas dibuatkan ke dalam matriks ternormalisasi ( $R$ ) sebagai berikut :

$$
\mathrm{R}=\begin{array}{cccccc}
0,3 & 1 & 0,3 & 0,3 & 0,25 & 0,25 \\
0,3 & 0,5 & 0,3 & 0,3 & 0,5 & 0,5 \\
0,6 & 0,5 & 1 & 0,6 & 1 & 1 \\
1 & 0,5 & 0,6 & 1 & 0,25 & 0,25 \\
0,6 & 1 & 0,3 & 0,6 & 0,25 & 0,25
\end{array}
$$

Langkah terakhir adalah proses pencarian perangkingan atau nilai terbaik dengan memasukkan setiap kriteria dan nilai bobot yang digunakan dalam perangkingan ini yaitu $\mathrm{W}=$ $[0,150,250,100,100,100,10]$, maka proses perangkingan adalah sebagai berikut :

$\mathrm{V} 1=(0,15)(0,3)+(0,25)(1)+(0,15)(0,3)+(0,15)(0,3)+(0,15)(0,25)+(0,15)(0,25)$

$=0,045+0,25+0,045+0,045+0,0375+0,0375$

$=0,46$

$\mathrm{V} 2=(0,15)(0,3)+(0,25)(0,5)+(0,15)(0,3)+(0,15)(0,3)+(0,15)(0,5)+(0,15)(0,5)$

$=0,045+0,125+0,045+0,045+0,075+0,075$

$=0,41$ 


$$
\begin{aligned}
& V 3=(0,15)(0,6)+(0,25)(0,5)+(0,15)(1)+(0,15)(0,6)+(0,15)(1)+(0,15)(1) \\
& =0,09+0,125+0,15+0,09+0,15+0,15 \\
& =0,755 \\
& \text { V4 }=(0,15)(1)+(0,25)(0,5)+(0,15)(0,6)+(0,15)(1)+(0,15)(0,25)+(0,15)(0,25) \\
& =0,15+0,125+0,09+0,15+0,0375+0,0375 \\
& =0,59 \\
& \text { V5 }=(0,15)(0,6)+(0,25)(1)+(0,15)(0,3)+(0,15)(0,6)+(0,15)(0,25)+(0,15)(0,25) \\
& =0,09+0,25+0,045+0,09+0,0375+0,0375 \\
& =0,55 \\
& \text { Total V }=0,46+0,41+0,755+0,59+0,55=2,765
\end{aligned}
$$

Nilai perhitungan perangkingan unutk setiap alternative dengan nilai Vi dapat dilihat dari tabel 8.

Tabel 8. Hasil Perangkingan

\begin{tabular}{ccc}
\hline Alternatif & Kode Alternatif & Hasil Perangkingan \\
\hline Simpati & $\mathrm{A} 1$ & 2,765 \\
\hline $\mathrm{XL}$ & $\mathrm{A} 2$ & 2,795 \\
\hline Indosat & $\mathrm{A} 3$ & 2,625 \\
\hline Smartfren & $\mathrm{A} 4$ & 2,805 \\
\hline Three (3) & $\mathrm{A} 5$ & 3,245
\end{tabular}

Sumber : Hasil Pengolahan Data (2020)

Selanjutnya alternative diurutkan dari nilai $\mathrm{V}$ yang terbesar ke nilai $\mathrm{V}$ yang terkecil, alternative dengan nilai $\mathrm{V}$ terbesar merupakan solusi yang terbaik, sebagai berikut:

Tabel 9. Hasil Pengurutan Alternatif

\begin{tabular}{ccc}
\hline Alternatif & Kode Alternatif & Hasil Perangkingan \\
\hline Three & A5 & 3,245 \\
\hline Smartfren & A4 & 2,805 \\
\hline XL & A2 & 2,795 \\
\hline Simpati & A1 & 2,765 \\
\hline Indosat & A3 & 2,625
\end{tabular}

Sumber : Hasil Pengolahan Data (2020) 
Dari hasil perhitungan diatas dapat ditentukan lima merek SimCard Provider yang berhak mendapatkan rangking teratas sesuai dari nilai $\mathrm{V} 1-\mathrm{V} 5$ dengan nilai terbesar yang pertama adalah Three (3), kedua adalah Smartfren, ketiga adalah XL, keempat adalah Simpati, dan kelima adalah Indosat.

Tabel 10. Data Pemilihan SimCard Provider

\begin{tabular}{ccc}
\hline Alternatif & Kode Alternatif & Hasil Perangkingan \\
\hline Three (3) & A5 & 1 \\
\hline Smartfren & A4 & 2 \\
\hline XL & A2 & 3 \\
\hline Simpati & A1 & 4 \\
\hline Indosat & A3 & 5 \\
\hline
\end{tabular}

Sumber : Hasil Pengolahan Data (2020)

Berdasarkan hasil perhitungan dan hasil pengurutan yang diterima untuk mendapatkan pilihan adalah alternative yang terbaik dari A1-A5 adalah A5 yaitu SimCard Provider Three (3).

Dari hasil perhitungan diatas dapat ditentukan lima merek SimCard Provider yang berhak mendapatkan rangking teratas sesuai dari nilai $\mathrm{V} 1-\mathrm{V} 5$ dengan nilai terbesar yang pertama adalah Three (3), kedua adalah Smartfren, ketiga adalah XL, keempat adalah Simpati, dan kelima adalah Indosat.

Tabel 11. Data Pemilihan SimCard Provider

\begin{tabular}{ccc}
\hline Alternatif & Kode Alternatif & Hasil Perangkingan \\
\hline Three (3) & A5 & 1 \\
\hline Smartfren & A4 & 2 \\
\hline XL & A2 & 3 \\
\hline Simpati & A1 & 4 \\
\hline Indosat & A3 & 5
\end{tabular}

Sumber : Hasil Pengolahan Data (2020)

Berdasarkan hasil perhitungan dan hasil pengurutan yang diterima untuk mendapatkan pilihan adalah alternative yang terbaik dari A1-A5 adalah A5 yaitu SimCard Provider Three (3).

\section{Kesimpulan}

Setelah dilakukan Analisa dalam penentuan pemilihan SimCard Provider dengan menggunakan metode Simple Additive Weighting (SAW) maka dapat diambil kesimpulan. Pada penelitian ini penentuan pemilihan SimCard Provider yang dilakukan dengan metode Simple Additive Weighting (SAW) dengan kriteria Sinyal, Harga, Paket Internet, Koneksi Internet, Bonus Telpon, dan Bonus Sms. Dari perhitungan preferensi (Vi) penulis dapat menghasilkan keputusan didapat nilai terbesar pada A5 dengan hasil 3,245 yang terpilih sebagai alternative terbaik dari seluruh alternative yang ada, yaitu Sim Card Provider Three (3) . Sim Card Provider Three (3) memiliki alternative terbaik karena memiliki sinyal yang bagus, jaringan internet yang stabil, paket telpon dan sms yang sesuai kebutuhan dan harga yang terjangkau untuk semua kalangan. 


\section{Daftar Pustaka}

Herlawati, Handayanto, R. T., \& Solikin. (2018). Neural network regression with support vector regression for land-use growth prediction. Proceedings of the 3rd International Conference on Informatics and Computing, ICIC 2018. https://doi.org/10.1109/IAC.2018.8780475

Informasi, S., \& Data, M. B. (2019). Jurnal simada. 02(02).

Karim, A., \& Purba, E. (2018). Sistem Informasi Pendataan Penduduk Kelurahan Kampung Mesjid Berbasis Web. Seminar Nasional Sains \& Teknologi Informasi (SENSAI), 537-545.

Khasanah, F. N. (2019). Metode Simple Additive Weighting Untuk Mendukung Pemilihan Laptop. PIKSEL : Penelitian IImu Komputer Sistem Embedded and Logic, 7(1), 91-100. https://doi.org/10.33558/piksel.v7i1.1657

Nainggolan, M. (2018). Analisis Perbandingan Ekuitas Merek Kartu Seluler Merek Simpati dan XL Prabayar. Jurnal Digest Marketing, 3(1), 1-6.

Prasetio, D., Arifin, Z., \& Septiarini, A. (2020). Sistem Pendukung Keputusan Persediaan Barang Menggunakan Metode Multi Objektif Optimization By Ratio Analysis. 19(1).

Rizan, O., Isnanto, B., \& Juniawan, F. P. (2019). Optimasi Pemilihan Model Pembelajaran Berbasis SCL Menggunakan Saw Method Pada Perguruan Tinggi XYZ. 7(1), 22-28.

Sugiyono. (2017). Metode Penelitian Kuantitatif, Kualitatif dan R\&D.

Supardi, Y. (2013). Sim Card. PT. Elex Media Komputindo.

Trianovie, S. (2018). Sigambal Dengan Menggunakan Program Borland Delphi 7 . 0 Sri Trianovie. Infotek, 3(1). 